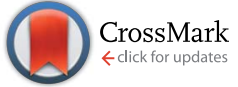

Cite this: RSC Adv., 2017, 7, 1026

Received 21st October 2016 Accepted 28th November 2016

DOI: $10.1039 / c 6 r a 25594 a$

www.rsc.org/advances

\section{Catalytic transfer hydrogenation of levulinic acid to $\gamma$-valerolactone over a bifunctional tin catalyst $\uparrow$}

\author{
Shaodan $\mathrm{Xu}^{\text {*ab }}{ }^{\mathrm{ab}}$ Deqing $\mathrm{Yu}^{\mathrm{a}}{ }^{\mathrm{T}} \mathrm{Tao} \mathrm{Ye}^{\mathrm{ac}}$ and Panpan $\mathrm{Tian}^{\mathrm{a}}$ \\ The conversion of biomass-derived levulinic acid (LA) to $\gamma$-valerolactone (GVL) is important but extremely \\ challenging due to the use of noble metal catalysts and high-pressure gaseous hydrogen. Here we describe \\ the transfer hydrogenation of LA to GVL using 2-propanol as hydrogen donor over a Sn modified silica \\ catalyst $\left(\mathrm{SnO}_{2} / \mathrm{SBA}-15\right)$ which gives high LA conversion (85.1\%) and GVL selectivity (95.2\%). Key to this \\ success is employing a simply synthesized $\mathrm{Sn}$-modified silica catalyst $\left(\mathrm{SnO}_{2} / \mathrm{SBA}-15\right)$ with both Lewis and \\ Brønsted acidity, which could synergistically catalyze the tandem steps of hydrogen transfer and \\ esterification, leading to successful transformation of LA to GVL.
}

\section{Introduction}

Biomass, which is regarded as a renewable feedstock, has attracted much attention for the production of fine chemicals and fuels. ${ }^{1-5}$ Many economically viable processes have been developed for the conversion of biomass., ${ }^{2,6}$ One efficient route is the fast pyrolysis and/or acidolysis of the cellulose and lignin feedstocks to various platform molecules, and then transformation of the platform molecules to the desired fuels and chemicals. $^{7-12}$ However, the biomass platform molecules have high oxygen content and various functional groups, which makes the transformation route complex and nonselective. ${ }^{1}$ Therefore, developing an efficient strategy to efficiently transform the biomass platform molecules is strongly desirable for producing high-quality fuels and chemicals.

Levulinic acid (LA), which can be easily produced from cellulosic feedstocks by acidolysis, has been recognized as one of the top-10 most promising platform molecules derived from biomass by the U.S. Department of Energy. ${ }^{13}$ One of the most important use of LA is to produce $\gamma$-valerolactone (GVL), which has been used as a high-quality solvent and fuel additive. ${ }^{\mathbf{1 4 - 2 0}}$ Recently, many catalysts, such as homogeneous $\mathrm{Pd}$ complex, ${ }^{21}$ heterogeneous $\mathrm{Ru} / \mathrm{C},{ }^{22,23} \mathrm{RuNi} / \mathrm{C},{ }^{24} \mathrm{Au} / \mathrm{ZrO}_{2},{ }^{25,26} \mathrm{Ru} /$ graphene, ${ }^{27}$ have successfully catalysed the transformation of LA to GVL by a hydrogenation and subsequent dehydration steps. ${ }^{28-34}$ However, it should be noted that noble metals and gaseous hydrogen are necessary in most of these cases, which

${ }^{a} Z$ Zhejiang Institute of Quality Inspection Science, Hangzhou 310018, China. E-mail: xushaodan6677@126.com

${ }^{b}$ Department of Chemistry, Zhejiang University, Hangzhou 310027, China 'MOE Key Laboratory of Macromolecular Synthesis and Functionalization, Department of Polymer Science and Engineering, Zhejiang University, Hangzhou 310027, China

$\dagger$ Electronic supplementary information (ESI) available. See DOI: $10.1039 / \mathrm{c} 6 \mathrm{ra} 25594 \mathrm{a}$ make their further application difficult due to the pricy cost of noble metals and hazardous gaseous hydrogen. Therefore, efficient production of GVL from LA without using noble metal catalysts and gaseous hydrogen is still challenging. Recently, transfer hydrogenation of LA using the organic molecules (e.g. formic acid, 2-propanol) as hydrogen sources have been extensively studied, which is regarded to be potentially important for LA conversion. In the transfer hydrogenation of LA, the $\mathrm{Zr}$ - and Ni-based catalysts have attracted much attention because of their non-noble feature and high efficiency. ${ }^{35-38}$ In these cases, the metal atoms were attached into the zeolite or organic polymer framework to form Lewis acid sites, which benefit the transfer hydrogenation reaction. Considering the importance of LA conversion, developing more efficient catalysts for this process is still necessary.

In the present work, we reported a Sn modified silica catalyst ( $\left.\mathrm{SnO}_{2} / \mathrm{SBA}-15\right)$, which is simply synthesized by grafting $\mathrm{Sn}$ sites on the surface of silica, could efficiently catalyse the transfer hydrogenation of LA to GVL using 2-propanol as hydrogen donor. For $\mathrm{SnO}_{2} / \mathrm{SBA}-15$ catalyst, the $\mathrm{Sn}$ sites are uniformly distributed on the $\mathrm{SiO}_{2}$ support and exhibited both Lewis and Brønsted acidity. It is observed that the Lewis and Brønsted acidity are benefit for the tandem reactions of transfer hydrogenation and dehydration, respectively, giving GVL yield at as high as $81.0 \%$. Importantly, the $\mathrm{SnO}_{2} / \mathrm{SBA}-15$ catalyst is very stable and recyclable, showing constant GVL yield in long reaction period in a fixed-bed reactor.

\section{Experimental}

\section{Sample preparation}

All chemicals were commercially available and directly used without further purification. The SBA-15 support was synthesized according to the method described in literature. ${ }^{39}$ 


\section{Synthesis of $\mathrm{SnO}_{2} / \mathrm{SBA}-15$ and $\mathrm{HL}-\mathrm{SnO}_{2} / \mathrm{SBA}-15$ (high-loading} $\mathrm{SnO}_{2} / \mathrm{SBA-15)}$

$5.0 \mathrm{~g}$ of SBA- 15 was dried in vacuum at $80^{\circ} \mathrm{C}$ for $24 \mathrm{~h}$, and then dispersed in $150 \mathrm{ml}$ of $p$-xylene. After ultrasonic treatment for $1 \mathrm{~h}$, a desired amount of dimethyldichlorostannane and $22 \mathrm{ml}$ of triethylamine was added, and the mixture was continuously stirred for another $10 \mathrm{~h}$ at room temperature. After washing with $p$-xylene and ethanol, and calcining at $600{ }^{\circ} \mathrm{C}$ for $2 \mathrm{~h}$ in flowing oxygen ( $5 \%$ in $\mathrm{N}_{2}$ ), the SBA-15 with grafted Sn species could be obtained. By adjusting the amount of dimethyldichlorostannane in the starting solution, the $\mathrm{SnO}_{2} / \mathrm{SBA}-15$ and $\mathrm{HL}-\mathrm{SnO}_{2} / \mathrm{SBA}-15$ with different $\mathrm{Si} / \mathrm{Sn}$ ratio could be obtained. The $\mathrm{SnO}_{2} / \mathrm{MCM}-41$ catalyst was synthesized in the same method as synthesizing $\mathrm{SnO}_{2} / \mathrm{SBA}-15$ except the use of MCM-41 as support instead of SBA-15.

\section{Sample characterization}

Nitrogen sorption isotherms were measured using a Micromeritics ASAP 2020M system. The samples were outgassed for $10 \mathrm{~h}$ at $200{ }^{\circ} \mathrm{C}$ before the measurements. The pore-size distribution was calculated using the Barrett-Joyner-Halenda (BJH) model. Titan ChemiSTEM and FEI Tecnai G2 F20 microscopes equipped with an EDAX detector were employed to acquire TEM, HAADF-STEM images, and energy dispersive X-ray spectrum (EDS) elemental maps. Powder X-ray diffraction patterns (XRD) were obtained with a Rigaku D/MAX 2550 diffractometer with $\mathrm{CuK} \alpha$ radiation $(\lambda=0.1542 \mathrm{~nm})$. The FTIR spectra of pyridine-adsorption were recorded on a Thermo-Fisher FTIR spectrometer. $15 \mathrm{mg}$ of sample in a cell was used for the pyridine-adsorption IR test. The pyridine vapor was admitted into the cell and adsorption lasted for $1 \mathrm{~h}$. Subsequently, the samples were heated up to $220{ }^{\circ} \mathrm{C}$ under vacuum and cooled down to RT for collecting the signal.

\section{Catalytic tests}

The reactions were performed in a $50 \mathrm{ml}$ high-pressure autoclave with a magnetic stirrer. The substrate, catalyst, and solvent were mixed in the reactor, then pure $\mathrm{N}_{2}$ was introduced to remove the air in autoclave and keep the $\mathrm{N}_{2}$ pressure at 0.7-0.8 MPa. Then, the autoclave was heated to a given temperature. After the reaction, the product was taken out from the reaction system and analyzed by gas chromatography (flame ionization detector) with a flexible quartz capillary column (100 $\mathrm{m}$ in length) coated with FFAP. The recyclability of the catalyst was tested by separating the catalyst solids from the reaction system by centrifugation, washing with large quantity of methanol and water, drying at $60{ }^{\circ} \mathrm{C}$, then the catalyst was reused in the next reaction. The reactions in the fixed-bed reactor were carried in a $10 \mathrm{ml}$ quartz tube with an oven to control the temperature. The catalysts were made into 1-2 mm particles and mixed with quartz particles with similar sizes, then the mixture was localized in the middle of the tube. The liquid substrates were injected into the reactor by a pump, and $\mathrm{N}_{2}$ flowed in the reactor during the whole reaction process.

\section{Results and discussion}

It is well known that ultra-small metal nanoclusters (e.g. Al, $\mathrm{Zr}$, Sn) could create Brønsted acidic sites from the surface hydroxyl groups. ${ }^{40}$ Therefore, it is possible to synthesize a metal catalyst with both Lewis and Brønsted acidity by loading uniformly dispersed metal species on an inert silica support. In this case, the mesoporous SBA-15 was employed as silica support because of the obvious advantage of the large surface area, which is expected to be favorable for the dispersion of acid sites as well as the diffusion of reactants. The Sn species are loaded on the SBA-15 support by a grafting method, ${ }^{\mathbf{4 0 , 4 1}}$ where the dimethyldichlorostannane was grafted the mesoporous silica of SBA15 by a condensation reaction with the silanol groups, followed by calcination to form hydroxyl group on Sn species (Scheme 1). The obtained $\mathrm{SnO}_{2} / \mathrm{SBA}-15$ has a $\mathrm{Si} / \mathrm{Sn}$ ratio at 53, as determined by inductively coupled plasma optical emission spectrometry (ICP-OES) (Table 1).

Fig. 1A shows the small-angle X-ray diffraction (XRD) pattern of $\mathrm{SnO}_{2} / \mathrm{SBA}-15$. In the region at $0.6-2^{\circ}$, three peaks obviously appeared indexing to the (100), (110) and (200) reflections of the hexagonal mesoporous arrays. ${ }^{39}$ Notably, the peaks assigning to $\mathrm{SnO}_{2}$ crystals at $\sim 34$ and $\sim 52^{\circ}$ are completely absent in the wide-angle XRD pattern of $\mathrm{SnO}_{2} / \mathrm{SBA}-15$ (Fig. 1B), which might be due to the low metal loading. Fig. 1C shows the nitrogen sorption isotherm of $\mathrm{SnO}_{2} / \mathrm{SBA}-15$, which exhibit typical IV curve with a hysteresis loop, assigning to typical mesoporous structure. Additionally, the $\mathrm{SnO}_{2} / \mathrm{SBA}-15$ exhibits a surface area at $359 \mathrm{~cm}^{2} \mathrm{~g}^{-1}$ and uniform pore diameter distribution at $6.5 \mathrm{~nm}$ (Fig. 1D, Table 1), which are slightly smaller than those of the as-synthesized SBA-15 (Fig. S1†). This phenomenon might be due to the successful grafting of Sn species in the mesopores of SBA- 15 .

Electronic microscopy images give direct observation of the $\mathrm{SnO}_{2} / \mathrm{SBA}-15$. Fig. 2a shows the high-angle annular dark-field scanning transmission electron microscopy (HAADF-STEM) by the Z-contrast, which exhibits high-quality mesoporous structure, in good agreement with the results of XRD pattern and $\mathrm{N}_{2}$

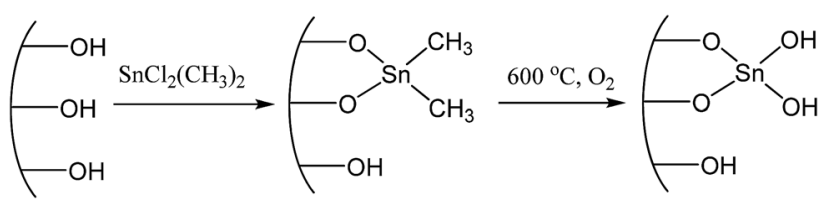

Scheme 1 Synthesis of $\mathrm{SnO}_{2} / \mathrm{SBA}-15$ by grafting $\mathrm{Sn}$ species on the SBA-15 support

Table 1 Structural parameters of various samples

\begin{tabular}{llll}
\hline Sample & Si/Sn ratio $^{a}$ & $S_{\text {BET }}\left(\mathrm{m}^{2} \mathrm{~g}^{-1}\right)$ & Pore width $(\mathrm{nm})$ \\
\hline SBA-15 & - & 565 & 7.5 \\
$\mathrm{SnO}_{2} / \mathrm{SBA}^{-15}$ & 53 & 359 & 6.5 \\
$\mathrm{HL}^{-S n O} \mathrm{SBA}_{2} / \mathrm{SB}-15$ & 13 & 320 & 6.3 \\
${ }^{a}$ By ICP analysis. & & &
\end{tabular}



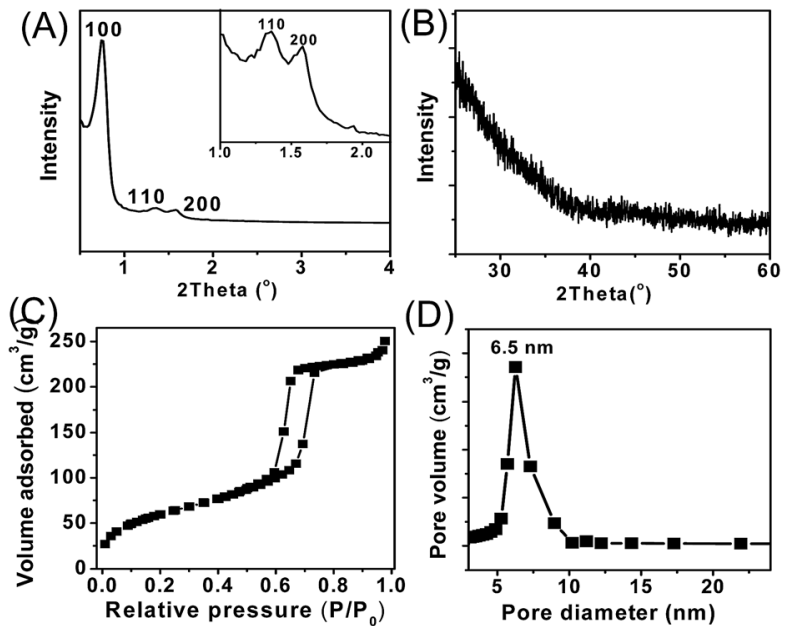

Fig. 1 (A) Small-angle and (B) wide angle XRD patterns, (C) $\mathrm{N}_{2}$ sorption isotherms, and (D) mesopore size distribution of $\mathrm{SnO}_{2} / \mathrm{SBA}-15$.
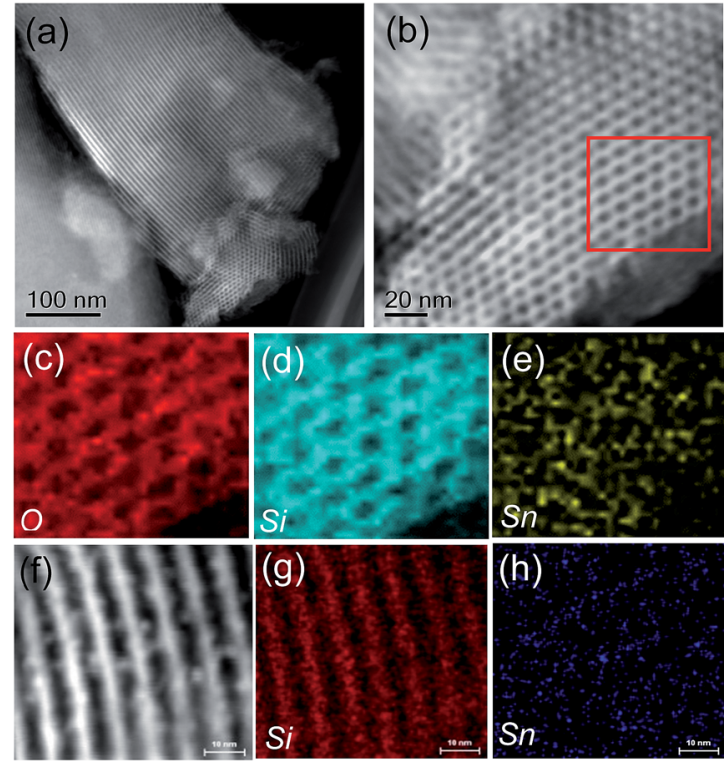

Fig. 2 (a and b) STEM images of $\mathrm{SnO}_{2} / \mathrm{SBA}-15$; (c) O, (d) Si and (e) Sn elemental maps of the red square in (b). (f) STEM image and (g) Si and (h) Sn EDS elemental maps of $\mathrm{HL}-\mathrm{SnO}_{2} / \mathrm{SBA}-15$.

sorption isotherms. Notably, it is difficult to directly observe the Sn species in the high-resolution STEM image (Fig. 2b), which might be due to the uniform dispersion of Sn species on the surface of SBA-15. The energy dispersive X-ray (EDX) mapping analysis gives clear observation of the distribution of $\mathrm{Sn}$ element. As shown in Fig. 2c-e, the Sn element has similar distribution to $\mathrm{Si}$ and $\mathrm{O}$ elements. Furthermore, energy dispersive spectra of randomly selected regions on $\mathrm{SnO}_{2} / \mathrm{SBA}-15$ give similar signals (Fig. S2 $\dagger$ ). These results indicate the uniform dispersion of $\mathrm{Sn}$ on $\mathrm{SnO}_{2} / \mathrm{SBA}-15$ sample. For comparison, Fig. $2 \mathrm{f}-\mathrm{h}$ show the electron microscopy characterization of $\mathrm{HL}-\mathrm{SnO}_{2} / \mathrm{SBA}-15$. Clearly, many nanoparticles could be obviously observed in the mesopores of the SBA-15, assigning to the aggregated Sn species because of high Sn loading.

The acidity of $\mathrm{SnO}_{2} / \mathrm{SBA}-15$ and $\mathrm{HL}-\mathrm{SnO}_{2} / \mathrm{SBA}-15$ was studied by pyridine-adsorption IR spectra. As shown in Fig. $3, \mathrm{SnO}_{2} / \mathrm{SBA}-$ 15 gave the obvious bands at 1453 and $1614 \mathrm{~cm}^{-1}$, which are assigned to the coordinative bound of pyridine on Lewis acid sites. ${ }^{42-44}$ Interestingly, the spectrum of $\mathrm{SnO}_{2} / \mathrm{SBA}-15$ also gives a band at $1531 \mathrm{~cm}^{-1}$, which is characteristic of pyridine adsorbed on the Brønsted acid sites. The band at $1491 \mathrm{~cm}^{-1}$ is from the contribution of pyridine adsorbed on both Lewis and Brønsted acid sites. These results indicate that $\mathrm{SnO}_{2} / \mathrm{SBA}-15$ has both Lewis and Brønsted acid sites, which should origin from the Sn atoms and silanolgroups, respectively. ${ }^{31,45}$ In contrast, the $\mathrm{HL}^{-\mathrm{SnO}_{2}} / \mathrm{SBA}$ 15 exhibited very weak band at $1531 \mathrm{~cm}^{-1}$, indicating the sparsely Brønsted acid on HL-SnO $2 /$ SBA-15, which might be due to the aggregation of Sn species could eliminate most of the $\mathrm{Sn}-\mathrm{OH}$ groups. Furthermore, the band of pyridine on the Lewis acid sites of $\mathrm{HL}-\mathrm{SnO}_{2} / \mathrm{SBA}-15$ appeared at $1446 \mathrm{~cm}^{-1}$, with a red shift of 7 $\mathrm{cm}^{-1}$ from that of $\mathrm{SnO}_{2} / \mathrm{SBA}-15\left(1453 \mathrm{~cm}^{-1}\right)$. The red shift in IR band suggests the weaker pyridine-Lewis acid interaction on HL$\mathrm{SnO}_{2} / \mathrm{SBA}-15$ than $\mathrm{SnO}_{2} / \mathrm{SBA}-15$. Similar phenomenon could also be observed in the band at $1491 \mathrm{~cm}^{-1}$ on $\mathrm{SnO}_{2} / \mathrm{SBA}-15$, which shifted to $1480 \mathrm{~cm}^{-1}$ on $\mathrm{HL}-\mathrm{SnO}_{2} / \mathrm{SBA}-15$. These results indicate the significant advantages of $\mathrm{SnO}_{2} / \mathrm{SBA}-15$ in both Lewis and Brønsted acidity compared with $\mathrm{HL}-\mathrm{SnO}_{2} / \mathrm{SBA}-15 .^{{ }^{46}}$

The catalytic study starts from the conversion of LA to GVL in 2-propanol solvent. As summarized in Table 2, SBA-15 support without any Sn species is inactive for the formation of GVL (entry 1). Interestingly, when $\mathrm{SnO}_{2} / \mathrm{SBA}-15$ was used as catalyst, the conversion of LA could reach $85.1 \%$ with GVL selectivity at as high as $95.2 \%$ (entry 2). In contrast, the $\mathrm{HL}-\mathrm{SnO}_{2} / \mathrm{SiO}_{2}$, which has the same individuals of $\mathrm{Sn}$ species and $\mathrm{SiO}_{2}$ support to $\mathrm{SnO}_{2} / \mathrm{SBA}-15$ catalyst, exhibits much lower LA conversion at only $4.9 \%$ (entry 3). Additionally, we also tested the catalytic performances of various transition metal oxides with Lewis acidity, including $\mathrm{Al}_{2} \mathrm{O}_{3}, \mathrm{SnO}_{2}, \mathrm{ZrO}_{2}$, which also give low LA conversion $(1.9-14.4 \%)$ and GVL selectivity $(<42 \%)$ (entries $4-6)$. These results indicate that the catalysts with only Lewis acidity is active for the transfer hydrogenation of LA to GVL, but $\mathrm{SnO}_{2} /$ SBA-15 with strong Lewis and Brønsted acidity is more efficient.

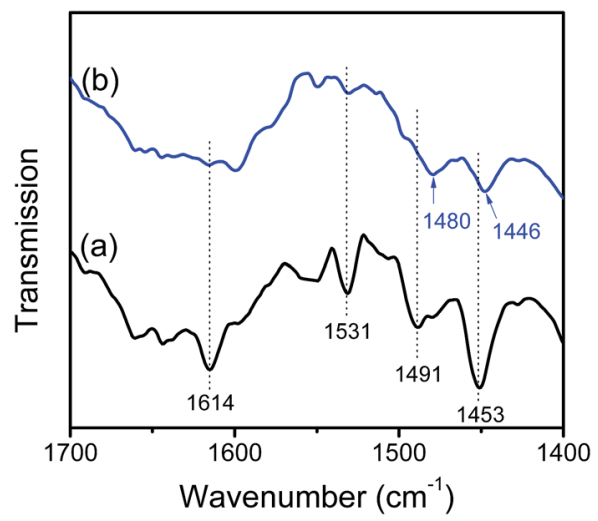

Fig. 3 Pyridine adsorption IR spectra of (a) $\mathrm{SnO}_{2} / \mathrm{SBA}-15$ and (b) $\mathrm{HL}$ $\mathrm{SnO}_{2} / \mathrm{SBA}-15$ 
Table 2 Catalytic data in conversion of LA to GVL using 2-propanol over various catalysts ${ }^{a}$

\begin{tabular}{llll}
\hline Entry & Catalyst & LA conv. (\%) & GVL Sel. (\%) \\
\hline 1 & $\mathrm{SBA}-15$ & $-^{b}$ & $-\overline{-}^{b}$ \\
2 & $\mathrm{SnO}_{2} / \mathrm{SBA}-15$ & 85.1 & $95.2^{c}$ \\
3 & $\mathrm{HL}^{c} \mathrm{SnO}_{2} / \mathrm{SBA}-15$ & 4.9 & 96.5 \\
4 & $\mathrm{Al}_{2} \mathrm{O}_{3}$ & 1.9 & $-{ }^{b}$ \\
5 & $\mathrm{SnO}_{2}$ & 3.9 & $-{ }^{b}$ \\
6 & $\mathrm{ZrO}_{2}$ & 14.4 & 42.1
\end{tabular}

${ }^{a}$ Reaction conditions: $3 \mathrm{mmol}$ of LA, $50 \mathrm{mmol}$ of 2-propanol, $140 \mathrm{mg}$ of catalyst, $110{ }^{\circ} \mathrm{C}, 8 \mathrm{~h} .{ }^{b}$ Undetectable. ${ }^{c}$ The by-products are mainly the lipid from the esterification of acid with 2-propanol.

According to the well-known Meerwein-Ponndorf-Verley reduction using 2-propanol as hydrogen donor over Lewis acid sites, ${ }^{47}$ it is reasonable to assume the conversion of LA to GVL should process the tandem steps of (I) transfer hydrogenation from 2-propanol to reduce the $\mathrm{C}=\mathrm{O}$ to $\mathrm{C}-\mathrm{OH}$ group on $\mathrm{LA}$ and (II) esterification of the $\mathrm{C}-\mathrm{OH}$ and $\mathrm{COOH}$ groups to form $\mathrm{GVL}$ (Scheme 2). On the basis of the proposed reaction process, we discussed the reasons why $\mathrm{SnO}_{2} / \mathrm{SBA}-15$ shows better catalytic performances than the $\mathrm{HL}-\mathrm{SnO}_{2} / \mathrm{SBA}-15$ by studying the reaction rate of each individual step, because the reaction rates in the beginning of the reactions at low conversion are sensitive to the activities of the catalysts. In order to understand the performances of the catalysts in each of the steps for transfer hydrogenation and esterification in LA-to-GVL reaction (Scheme 3), we employ different substrates to split the LA-toGVL process into two individual reactions, as presented in Scheme 2, which are (I) transfer hydrogenation of $\mathrm{C}=\mathrm{O}$ in 2pentanone with 2-propanol to $\mathrm{C}-\mathrm{OH}$ and (II) esterification of 2-
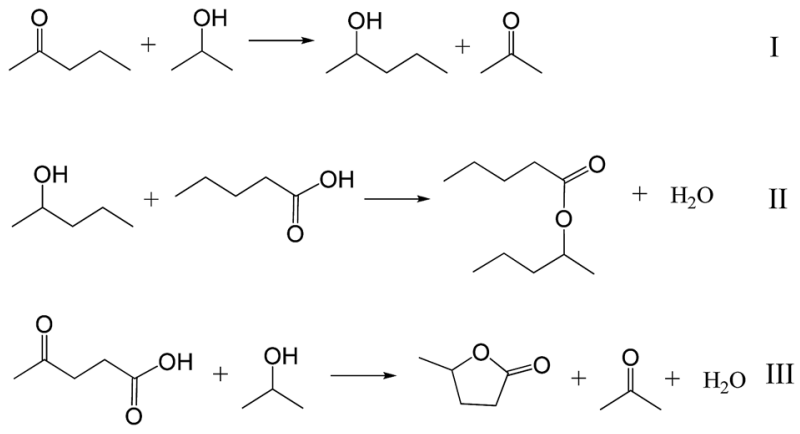

Scheme 2 The model reactions of (I) hydrogen transfer from 2-proponal to reduce the $\mathrm{C}=\mathrm{O}$ group, (II) esterification of $\mathrm{C}-\mathrm{OH}$ and $\mathrm{COOH}$ groups, and (III) transformation of LA to GVL using 2-pentonal as hydrogen donor.

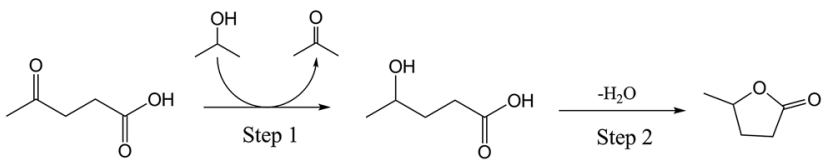

Scheme 3 The two steps in LA-to-GVL process. pentanol with $n$-pentanoic acid to ester. This method has been widely used to study the contribution of catalysts in the transformation with multiple steps ${ }^{48}$ which benefit the investigation on the catalytic activity of the catalyst in the individual steps, thus to understand the rate control step and the origin of high activity. Table 3 lists the reaction rates of the $\mathrm{Sn}$-based catalysts in the individual reactions of (I) hydrogen transfer from 2propanol to reduce the $\mathrm{C}=\mathrm{O}$ group and (II) esterification of $\mathrm{C}-$ $\mathrm{OH}$ and $\mathrm{COOH}$ groups and the combined reaction of (III) transformation of LA to GVL using 2-propanol as hydrogen donor (Scheme 2). The reaction rates are obtained by the catalytic conversion at the beginning of each reaction within a short time of $20 \mathrm{~min}$. It is worth emphasizing that the intramolecular esterification to form GVL in the LA-to-GVL process could occur even in the absence of Brønsted acid catalyst, ${ }^{37,38}$ here the intermolecular esterification (reaction II) was employed to slow down the reaction rate for clarifying the different activities of various catalysts. Clearly, the SBA-15 without Sn species failed to catalyze all the reactions (entry 1 in Table 3 ). Interestingly, $\mathrm{SnO}_{2} / \mathrm{SBA}-15$ is very active for both the hydrogen transfer (reaction I, Scheme 2) and esterification (reaction II, Scheme 2), giving reaction rate at 16.7 and $28.1 \mathrm{mmol} \mathrm{g}^{-1} \mathrm{~h}^{-1}$, respectively. In the conversion of LA to GVL (reaction III, Scheme 2), the rate of producing GVL over $\mathrm{Sn} / \mathrm{SiO}_{2}$ could reach as high as $12.1 \mathrm{mmol} \mathrm{g}^{-1} \mathrm{~h}^{-1}$ (entry 2 in Table 3 ). In contrast, the $\mathrm{HL}-\mathrm{SnO}_{2} /$ SBA-15 which has only Lewis acidity, could solely catalyze the hydrogen transfer reaction and exhibit reaction rate at $3.1 \mathrm{mmol}$ $\mathrm{g}^{-1} \mathrm{~h}^{-1}$ (entry 3 in Table 3 ). Considering hydrogen transfer is a control step in the reaction, the obviously higher activities of $\mathrm{SnO}_{2} / \mathrm{SBA}-15$ than $\mathrm{HL}-\mathrm{SnO}_{2} / \mathrm{SBA}-15$ in hydrogen transfer step play important role to make it an efficient catalyst. As well, the high activity in the esterification step might also contribute to the good catalytic performances of $\mathrm{SnO}_{2} / \mathrm{SBA}-15$.

Importantly, the $\mathrm{SnO}_{2} / \mathrm{SBA}-15$ catalyst is reusable. After each reaction run, the catalyst can be easily separated from the reaction system and reused in the next run by simple washing and drying. As shown in Fig. 4, in the recycling process, a constant LA conversion $(\sim 85.0 \%)$ and GVL selectivity ( $\sim 95.0 \%$ ) could be obtained. Moreover, the performances of the fresh catalyst and used catalysts after the $6^{\text {th }}$ run in the transfer hydrogenation reaction also have been tested in a shortened

Table 3 Reactions rates of various catalysts in the model reactions listed in Scheme 2

\begin{tabular}{|c|c|c|c|c|}
\hline \multirow[b]{2}{*}{ Entry } & \multirow[b]{2}{*}{ Catalyst } & \multicolumn{3}{|c|}{ Reaction rate $\left(r_{0}, \mathrm{mmol} \mathrm{g}^{-1} \mathrm{~h}^{-1}\right)$} \\
\hline & & Reaction $\mathrm{I}^{a}$ & Reaction II $^{b}$ & Reaction III ${ }^{c}$ \\
\hline 1 & SBA-15 & $-^{d}$ & $<1.0$ & $-^{d}$ \\
\hline 2 & $\mathrm{SnO}_{2} / \mathrm{SBA}-15$ & 16.7 & 28.1 & 12.1 \\
\hline 3 & $\mathrm{HL}_{-S n O} / \mathrm{SBA}-15$ & 4.9 & $<1.0$ & $<1.0$ \\
\hline
\end{tabular}




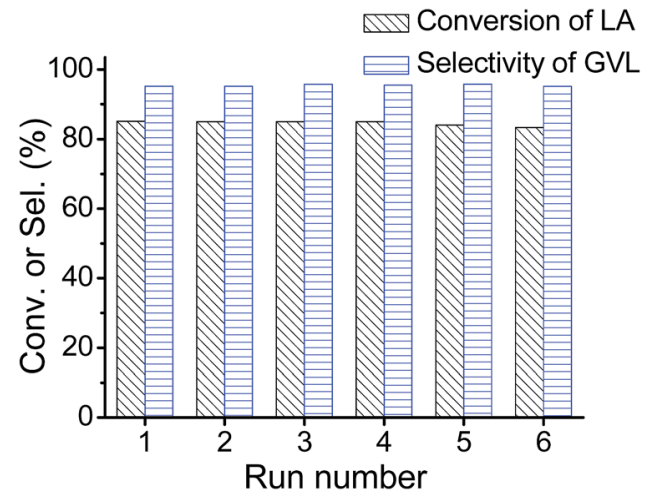

Fig. 4 Catalytic data of $\mathrm{SnO}_{2} / \mathrm{SBA}-15$ in the recyclability test. Reaction at $100{ }^{\circ} \mathrm{C}$, reactor volume at $10 \mathrm{ml}, 0.2 \mathrm{~g}$ of $\mathrm{SnO}_{2} / \mathrm{SBA}-15,2.0 \mathrm{wt} \% \mathrm{LA}$ in

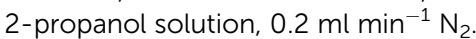

reaction time, where similar catalytic performances were obtained, indicating the high stability of the Sn catalyst (entries 1, 2 in Table 4). By ICP analysis, the Sn leaching is negligible during the recycling process. The conversion of LA to GVL was also performed in a fixed-bed reactor using a mixture of LA and 2-propanol as feed (Fig. S3A $\dagger$ ). In the catalytic tests, no obvious decrease in LA conversion and GVL selectivity was observed for a $50 \mathrm{~h}$ reaction (Fig. $\mathrm{S} 3 \mathrm{~B} \dagger$ ). On the other hand, the use of SBA-15 as supports has been compared with another typical silica support of MCM-41. The $\mathrm{SnO}_{2} / \mathrm{MCM}-41$ catalyst exhibits very comparable performance to that of $\mathrm{SnO}_{2} / \mathrm{SBA}-15$ (entry 3 in Table 4), suggesting that the silica support have little influence on the catalytic performances of Sn catalysts.

Table 4 Catalytic data in conversion of LA to GVL using 2-propanol over various catalysts in a shorten reaction time ${ }^{a}$

\begin{tabular}{llll}
\hline Entry & Catalyst & LA conv. (\%) & GVL Sel. (\%) \\
\hline 1 & Fresh $\mathrm{SnO}_{2} /$ SBA-15 & 59.5 & 91.0 \\
2 & ${\text { Used } \mathrm{SnO}_{2} / \mathrm{SBA}-15^{b}}^{b}$ & 56.2 & 93.7 \\
3 & $\mathrm{SnO}_{2} / \mathrm{MCM}^{-41}$ & 63.4 & 88.1
\end{tabular}

${ }^{a}$ Reaction conditions: $3 \mathrm{mmol}$ of LA, $50 \mathrm{mmol}$ of 2-propanol, $140 \mathrm{mg}$ of catalyst, $110{ }^{\circ} \mathrm{C}, 4 \mathrm{~h} .{ }^{b}$ The catalyst after the 6 run in the recyclability test.

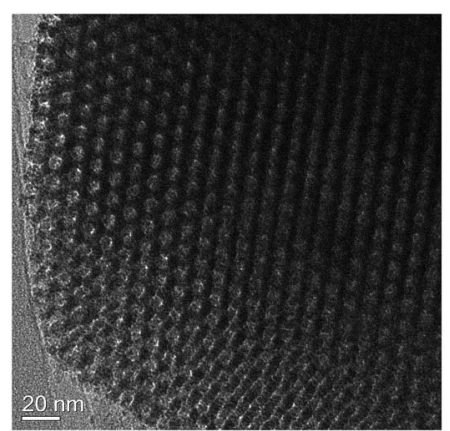

Fig. 5 TEM images of the randomly selected regions on the used $\mathrm{SnO}_{2} / \mathrm{SBA}-15$.
By TEM analysis (Fig. 5), the $\mathrm{SnO}_{2} / \mathrm{SBA}-15$ catalyst after a $50 \mathrm{~h}$ run still exhibited high-quality mesoporous structure. More importantly, no aggregation of Sn species was observed in the used $\mathrm{SnO}_{2} / \mathrm{SBA}-15$ catalyst, indicating the good stability of the catalysts. The high activity and selectivity combined with the good stability of $\mathrm{SnO}_{2} / \mathrm{SBA}-15$ catalyst make it potentially important for wide applications in the future.

\section{Conclusions}

In summary, we reported the transfer hydrogenation of LA to GVL using 2-propanol as hydrogen donor over a Sn modified silica catalyst $\left(\mathrm{SnO}_{2} / \mathrm{SBA}-15\right)$ which gives high LA conversion $(85.1 \%)$ and GVL selectivity (95.2\%). The good catalytic performance is reasonably attributed to the strong Lewis acid sites on $\mathrm{SnO}_{2} / \mathrm{SBA}-15$, which could efficiently catalyze the individual reactions of hydrogen transfer, as well as the Brønsted acidity, which is benefit for the esterification step, thus leading to an efficient LA-to-GVL process without using noble metals and gaseous hydrogen. Although it is still difficult to conclude that the transfer hydrogenation excelled in LA conversion efficiency, because the LA concentration in transfer hydrogenation tests is usually lower than that in direct hydrogenation cases, the transfer hydrogenation strategy indeed offers new ideas in developing alternative pathways in LA conversion. It is expected that this work can be potentially used to develop efficient catalysts and processes for the conversion of other biomass platform molecules.

\section{Acknowledgements}

This work is supported by the Science and Technology Project of General Administration of Quality Supervision, Inspection and Quarantine of the People's Republic of China (AQSIQ, No. 2014QK203).

\section{Notes and references}

1 G. W. Huber, S. Iborra and A. Corma, Chem. Rev., 2006, 106, 4044.

2 L. Wang, H. Wang and F.-S. Xiao, ChemSusChem, 2014, 7, 402.

3 D. Mohan, C. U. Pittman and P. H. Steele, Energy Fuels, 2006, 20, 848 .

4 D. M. Alonso, J. Q. Bond and J. A. Dumensic, Green Chem., 2010, 12, 1493.

5 B. Hu, K. Wang and M. M. Titirici, Adv. Mater., 2010, 22, 813.

6 F. Clippel, M. Dusselier and B. F. Sels, J. Am. Chem. Soc., 2012, 134, 10089.

7 Y. Roman-Leshkov, J. N. Chheda and J. A. Dumensic, Science, 2006, 312, 1933.

8 A. V. Bridgwater, Biomass Bioenergy, 2012, 38, 68.

9 P. Lenihan, A. Orozco and G. M. Walker, Chem. Eng. J., 2010, 156, 395.

10 T. Vom Stein, P. Grande and P. D. de Maria, Green Chem., 2010, 12, 1844. 
11 S. Suganuma, K. Nakajima and M. Hara, J. Am. Chem. Soc., 2008, 130, 12787.

12 S. Van de Vyver, L. Peng and B. F. Sels, Green Chem., 2010, 12, 1560.

13 M. Mascal and E. B. Nikitin, Green Chem., 2010, 12, 370.

14 W. R. H. Wright and R. Palkovits, ChemSusChem, 2012, 5, 1657.

15 P. P. Upare, J.-M. Lee and J.-S. Chang, J. Ind. Eng. Chem., 2011, 17, 287.

16 D. J. Braden, C. A. Henao and J. A. Dumesic, Green Chem., 2011, 13, 1755.

17 H. A. Schuette and R. W. Thomas, J. Am. Chem. Soc., 1930, 52, 3010.

18 L. Deng, J. Li and Q.-X. Guo, Angew. Chem., Int. Ed., 2009, 121, 6651.

19 F. M. A. Geilen, B. Engendahl and W. Leitner, Angew. Chem., Int. Ed., 2010, 122, 5642.

20 F. M. A. Geilen, B. Engendahl and W. Lritner, J. Am. Chem. Soc., 2011, 133, 14349.

21 C. Ortiz-Cervantes, M. Flores-Alamo and J. J. Garcia, ACS Catal., 2015, 5, 1424.

22 L. E. Manzer, Appl. Catal., A, 2004, 272, 249.

23 Z.-P. Yan, L. Lin and S. Liu, Energy Fuels, 2009, 23, 3853.

24 Y. Yang, G. Gao and F. W. Li, ACS Catal., 2014, 5, 1419.

25 X.-L. Du, L. He and K.-N. Fan, Angew. Chem., Int. Ed., 2011, 50, 7815.

26 X.-L. Du, Q.-Y. Bi and K.-N. Fan, ChemSusChem, 2011, 4, 1838.

27 J. J. Tan, J. L. Cui and Y. W. Li, ACS Catal., 2015, 5, 7379.

28 C. Xie, J. L. Song and B. X. Han, ACS Sustainable Chem. Eng., 2016, 4, 6231.

29 H. P. Winoto, B. S. Ahn and J. Jae, J. Ind. Eng. Chem., 2016, 40, 62.

30 A. H. Valekar, K.-H. Cho and Y. K. Hwang, Green Chem., 2016, 18, 4542 .
31 M. J. Gilkey and B. J. Xu, ACS Catal., 2016, 6, 1420.

32 S. S. Enumula, V. R. B. Gurram and S. R. R. Kamaraju, $R S C$ $A d v .$, 2016, 6, 20230.

33 J. L. Song, L. Q. Wu and B. X. Han, Green Chem., 2015, 17, 1626.

34 W. R. H. Wright and R. Palkovits, ChemSusChem, 2012, 5, 1657.

35 L. Bui, H. Luo and Y. Roman-Leshkov, Angew. Chem., Int. Ed., 2013, 52, 8022.

36 R. S. Assary, L. A. Curtiss and J. A. Dumensic, ACS Catal., 2013, 3, 2694.

37 J. L. Song, L. Q. Wu and B. X. Han, Green Chem., 2015, 17, 1626.

38 J. Yuan, S. S. Li and K.-N. Fan, Energy Environ. Sci., 2013, 6, 3308.

39 D. Y. Zhao, J. L. Feng and G. D. Stucky, Science, 1998, 279, 548.

40 L. Wang, J. Zhang and F.-S. Xiao, J. Mater. Chem. A, 2014, 2, 3725.

41 A. Corma, M. T. Navarro and M. Renz, J. Catal., 2003, 219, 242.

42 F. Babou, G. Coudurier and J. C. Vedrine, J. Catal., 1995, 152, 341.

43 M. I. Zaki, M. A. Hasan and L. Pasupulety, Colloids Surf., A, 2001, 190, 261.

44 X. C. Wang, J. C. Yu and X. Z. Fu, J. Photochem. Photobiol., A, 2006, 179, 339.

45 B. K. Chethana and S. H. Mushrif, J. Catal., 2015, 323, 158.

46 A. M. R. Galletti, C. Antonetti and M. Martinelli, Green Chem., 2012, 14, 688.

47 A. Corma, M. E. Domine and S. Valencia, J. Am. Chem. Soc., 2002, 124, 3194.

48 L. Wang, J. Zhang and F.-S. Xiao, ACS Catal., 2015, 5, 2727. 